\title{
Innate immune cells express IL-17A/F in acute generalized exanthematous pustulosis and generalized pustular psoriasis
}

\author{
M. Kakeda $\cdot$ Christoph Schlapbach • \\ G. Danelon $\cdot$ M. M. Tang $\cdot$ V. Cecchinato \\ N. Yawalkar $\cdot$ M. Uguccioni
}

Received: 1 May 2014/Revised: 23 June 2014/Accepted: 10 July 2014/Published online: 17 July 2014

(c) Springer-Verlag Berlin Heidelberg 2014

\begin{abstract}
Acute generalized exanthematous pustulosis (AGEP) and generalized pustular psoriasis (GPP) are rare pustular skin disorders with systemic involvement. IL-17A/ $\mathrm{F}$ is a proinflammatory cytokine involved in various neutrophilic inflammatory disorders. Here we show that IL$17 \mathrm{~A} / \mathrm{F}$ is highly expressed by innate immune cells such as neutrophils and mast cells in both AGEP and GPP.
\end{abstract}

Keywords IL-17A/F · AGEP · GPP · Innate immune cells $\cdot$ Mast cells $\cdot$ Neutrophils $\cdot$ Macrophages

$\begin{array}{ll}\text { Abbreviations } \\ \text { AGEP } & \text { Acute generalized exanthematous pustulosis } \\ \text { GPP } & \text { Generalized pustular psoriasis } \\ \text { IL-36Ra } & \text { IL-36 receptor antagonist } \\ \text { Th17 } & \text { T helper 17 } \\ \text { IL-17 } & \text { Interleukin 17A/F }\end{array}$

M. Kakeda, C. Schlapbach and G. Danelon contributed equally to this study.

Electronic supplementary material The online version of this article (doi:10.1007/s00403-014-1488-0) contains supplementary material, which is available to authorized users.

M. Kakeda · C. Schlapbach $(\bowtie) \cdot$ M. M. Tang · N. Yawalkar Department of Dermatology, Inselspital Bern University

Hospital, 3010 Bern, Switzerland

e-mail: christoph.schlapbach@insel.ch

M. Kakeda

Department of Dermatology, Mie University Graduate School of

Medicine, Tsu, Mie, Japan

G. Danelon · V. Cecchinato · M. Uguccioni

Institute for Research in Biomedicine, Bellinzona, Switzerland

\section{Introduction}

Acute generalized exanthematous pustulosis (AGEP) is a rare drug-induced skin reaction. It is characterized by an acute erythematous rash with numerous sterile pustules, accompanied by fever and neutrophilia [18]. Drug specific $\mathrm{T}$ cells are implicated in pathogenesis of AGEP, some of which have been shown to exhibit a phenotype consistent with Th17 cells $[1,15,16]$.

Generalized pustular psoriasis (GPP) is characterized by recurrent eruptions of sterile pustules on erythematous skin, high-grade fever and neutrophilia. In GPP and in a subset of AGEP, mutations of the IL-36 receptor antagonist (IL-36Ra) have been shown to lead to unregulated secretion of inflammatory cytokines [10].

IL-17A/F and Th17 cells have been identified as key players in the pathogenesis of auto-inflammatory disease. IL$17 \mathrm{~A} / \mathrm{F}$ is a potent inducer of tissue inflammation and neutrophil recruitment [12]. Although the key role of IL-17A/F/ Th17 cells in the pathogenesis of plaque psoriasis is well described [5], its expression in AGEP and GPP has not been studied in detail. Therefore, we sought to investigate the expression and distribution of IL-17A/F and its cellular source in AGEP and GPP in comparison to normal human skin.

\section{Materials and methods \\ Samples from patients}

The study was approved by the local Medical Ethics Committee. After informed consent, tissue samples were obtained from patients with AGEP $(n=8)$ and GPP $(n=8)$. Diagnosis was based on the EuroSCAR validation score [2] for AGEP and on clinical and histological 
features for GPP. Normal skin was obtained from healthy individuals who underwent surgery for esthetic reasons $(n=7$, median age 50 years).

The culprit drugs identified in our patients included amoxicillin-clavulanic acid (2 patients), terbinafine ( 2 patients), amoxicillin, clarithromycin, clindamycin and ibuprofen.

GPP samples were from 8 patients (5 female and 3 male) with the median age of 58 years (range 22-89 years).

Immunohistochemistry and immunofluorescence

Tissue sections from formalin-fixed, paraffin-embedded blocks were used for immunohistochemical and immunofluorescence staining as previously described [17, 22].

Goat anti-human IL-17A/F (AF-317-NA, R\&D), rabbit anti-human CD3 (A0452, DAKO), mouse anti-human CD68 (EBM11, DAKO), mouse anti-human CD66b (555723, Becton-Dickinson), and rabbit anti-human mast cell tryptase (sc-32889, Santa Cruz) were used. For detecting IL-17A/F a goat HRP polymer kit (GHP516H, Biocare Medical) was used. For double immunohistochemistry both the goat HRP polymer kit and MACH4 Universal mouse/rabbit AP-Polymer Kit (M4U536H, Biocare Medical) were used.

IL-17A/F was detected by immunofluorescence using either donkey anti-goat/Alexa Fluor 488 (A-11055) or rabbit anti-goat/Alexa Fluor 488 (A-11078). CD3 and mast cell tryptase were detected with donkey anti-rabbit/Alexa Fluor 594 (A-21207), CD68 was detected with a rabbit anti-mouse/Alexa Fluor 594 (A-11062), all from Invitrogen. Eosinophil cationic protein (ECP) was detected with monoclonal mouse anti-human ECP antibody (Pharmacia Diagnostics $\mathrm{AB}$, Sweden) followed by goat anti-mouse IgG2a/Alexa Fluor594 (A21135, Invitrogen).

Quantitative analysis was performed using the digital image analysis system NIS-Elements Software BR 2.30 by two independent observers and $3 \mathrm{HPF} / \mathrm{biopsy}$, as previously described [22]. Papillary dermis was defined as the part of the dermis that is intertwined with the rete ridges of the epidermis and is composed of fine and loosely arranged collagen fibers. The reticular dermis was defined as the part of the dermis under the papillary dermis, composed of dense irregular connective tissue.

In-situ hybridization

${ }^{35} \mathrm{~S}$-labeled sense and antisense IL-17A/F mRNA probe, $333 \mathrm{bp}$ in length and corresponding to position 143-475 bp of the human IL-17A/F sequence (NM_002190.2), were generated by in vitro transcription (10 999644001 , Roche). In situ hybridization was performed as previously described [11, 23].

\section{Results}

IL-17A/F positive cells in AGEP, GPP and normal skin

In normal skin, few IL-17A/ $\mathrm{F}^{+}$cells were observed in the upper dermis only (Fig. 1a). In AGEP, IL-17A/F $\mathrm{F}^{+}$cells were found in subcorneal pustules and, to a lesser extent, in the epidermis near pustules and the upper dermis (Fig. 1b). Similar findings were seen in GPP (Fig. 1c). Quantitative analysis of IL-17A/F ${ }^{+}$cells confirmed statistically significant differences in IL-17A/F expression between normal skin and AGEP and GPP, respectively (Fig. 1d).

In situ IL-17A/F mRNA expression

To confirm IL-17A/F gene expression in the skin, in situ hybridization was performed (Fig. 1h-j). IL-17A/F transcript expression was detected in normal skin, AGEP, and GPP. IL-17A/F mRNA co-localized with IL-17A/F protein expression, as detected by immunohistochemical staining in consecutive slides (Fig. 1e-g), thus confirming IL-17A/ $\mathrm{F}$ production in situ.

\section{Double immunostaining}

To determine the phenotype of cells expressing IL-17A/F, double immunohistochemical staining was performed with markers for neutrophils (CD66b) or T-lymphocytes (CD3) (Fig. 2a-f). In both AGEP and GPP, almost all cells in subcorneal pustules were $\mathrm{CD} 66 \mathrm{~b}^{+} / \mathrm{IL}-17 \mathrm{~A} / \mathrm{F}^{+}$neutrophils (Fig. 2a, c). In the epidermis and upper dermis, some IL$17 \mathrm{~A} / \mathrm{F}^{+} / \mathrm{CD} 6 \mathrm{~b}^{-}$cells were seen (Fig. $2 \mathrm{a}-\mathrm{c}$ ). The few $\mathrm{CD}^{+}$cells found in pustules did not co-express IL-17A/F (Fig. 2d, f). In the dermis, only a few IL-17A/F $\mathrm{F}^{+} / \mathrm{CD}^{+} \mathrm{T}$ cells were observed (Fig. 2e). Therefore, neutrophils appear to be the main source of IL-17A/F in pustules.

Furthermore, double immunofluorescence analysis was performed using markers for T-lymphocytes (CD3), macrophages and dendritic cells (CD68), mast cells (tryptase) (Fig. 3a-c) and for eosinophils (eosinophil cationic protein; ECP [19]; Suppl. Fig. 1). In both AGEP and GPP, IL$17 \mathrm{~A} / \mathrm{F}$ co-localized frequently with tryptase and CD68, respectively. $\mathrm{CD}^{+} / \mathrm{IL}-17 \mathrm{~A} / \mathrm{F}^{+}$cells were only scarcely detected, whereas eosinophils where not found to express any IL-17A/F in AGEP.

\section{Discussion}

Here we demonstrate on both the mRNA and the protein level that IL-17A/F-expressing cells are significantly 


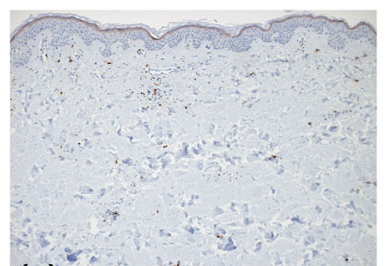

(a) Normal

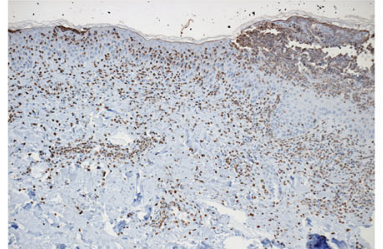

(b)

AGEP

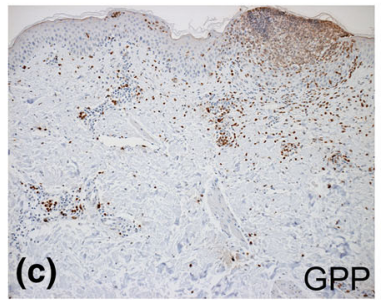

(d)

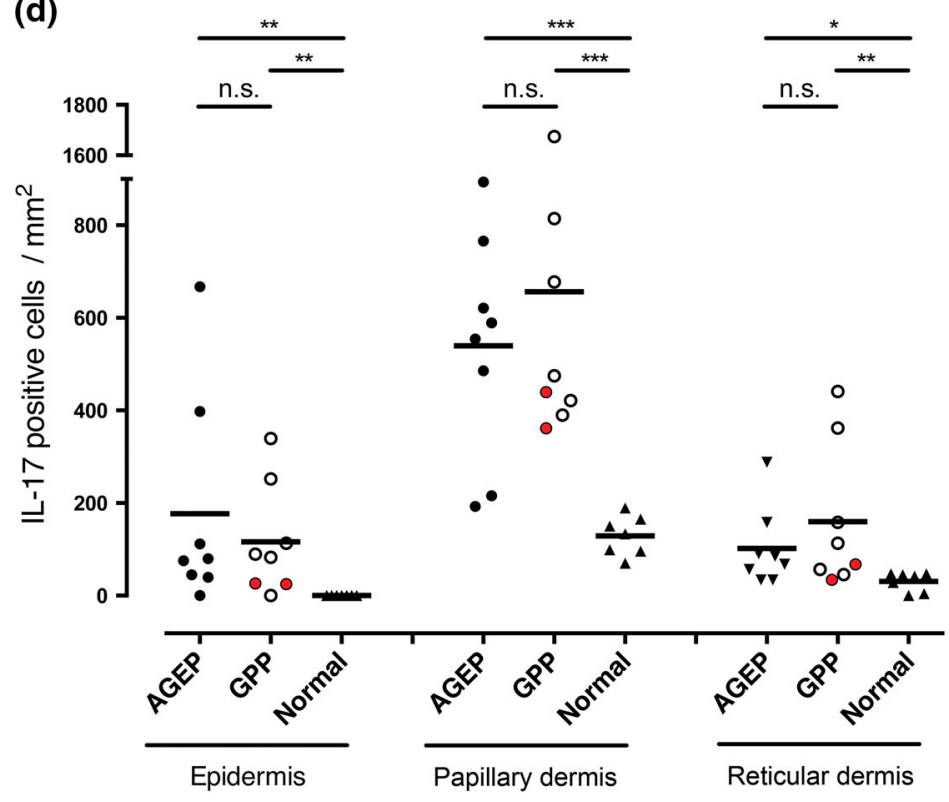

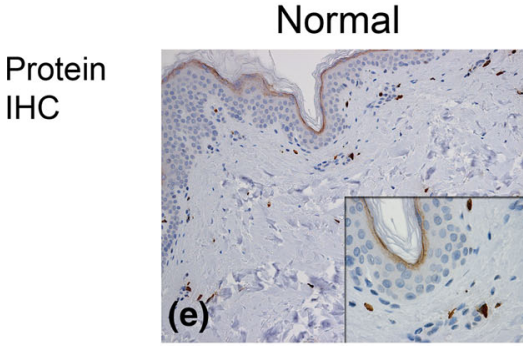
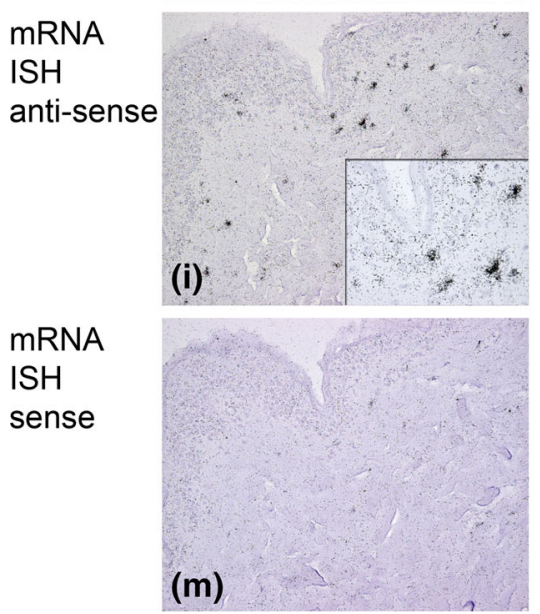
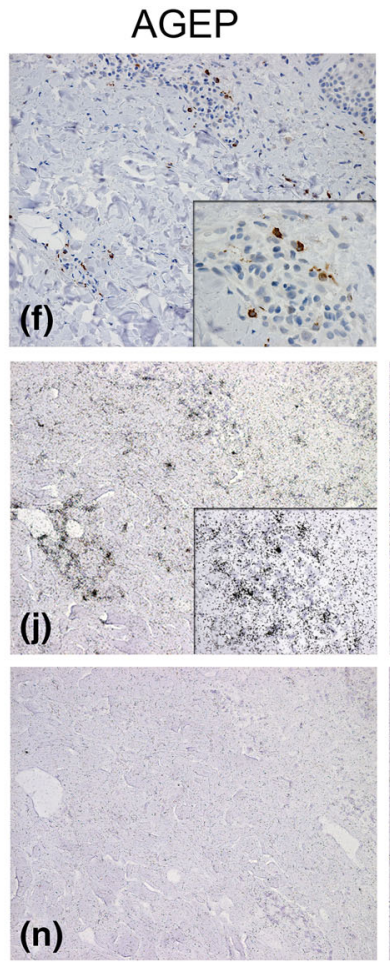

(n)

(o)
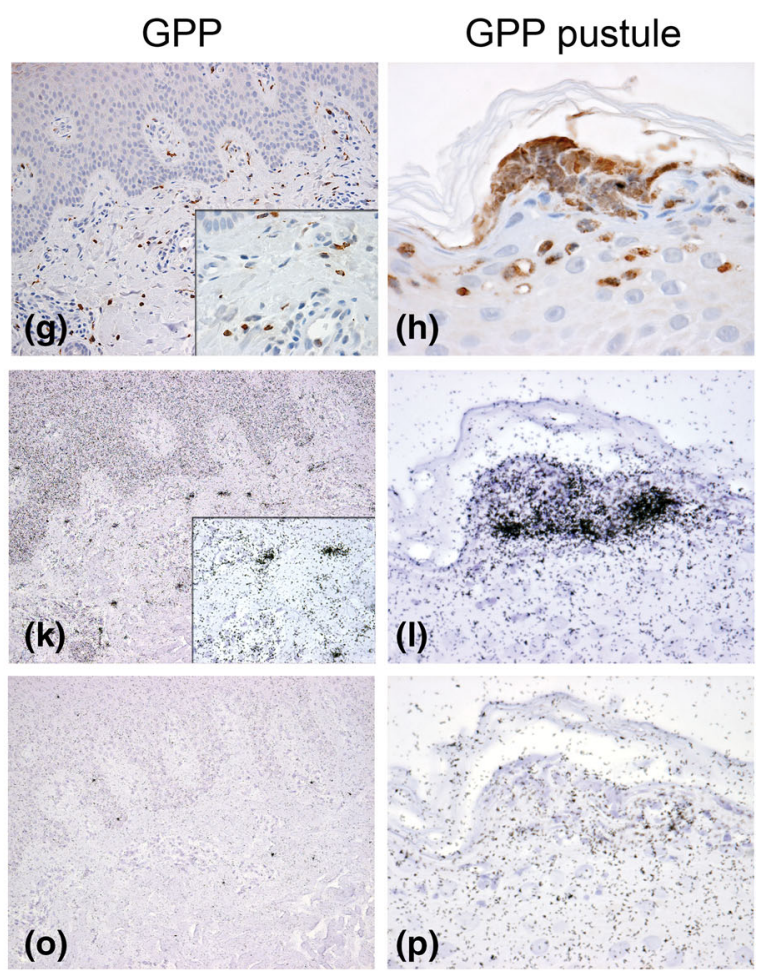

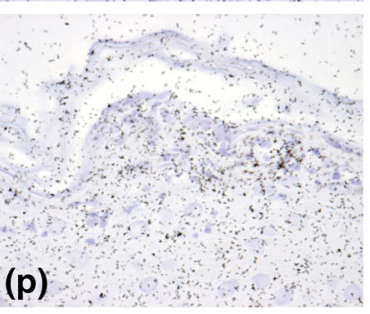

Fig. 1 IL-17A/F expression in normal skin, AGEP, and GPP. Representative immunohistochemical staining of IL-17 in the skin of a normal control, $\mathbf{b}$ acute generalized exanthematous pustulosis $(A G E P)$, and $\mathbf{c}$ generalized pustular psoriasis $(G P P)$. $\mathbf{d}$ The number of IL-17 positive cells in epidermis without pustules, upper dermis, and deep dermis of AGEP, GPP, and normal skin. For GPP, data points with red center indicate patients with "GPP + PV", data points with white center indicate patients with "GPP without PV". Mann-
Whitney $U$ test. $* p<0.05, * * p<0.01, * * * p<0.001$, n.s. not significant. e-h Immunohistochemical analysis of IL-17A/F expression in normal skin, AGEP and GPP. i-p Analysis of IL-17 mRNA tissue expression performed by in situ hybridization on serial sections shows co-localization of IL-17 mRNA (i-l) with IL-17 protein (e-h). Original magnification $\times 100(\mathbf{a}-\mathbf{c}), \times 200(\mathbf{e}-\mathbf{j})$, insets $\times 800(\mathbf{e}-\mathbf{g}, \mathbf{i}-$ k). $I H C$ immunohistochemistry, $I S H$ in situ hybridization 


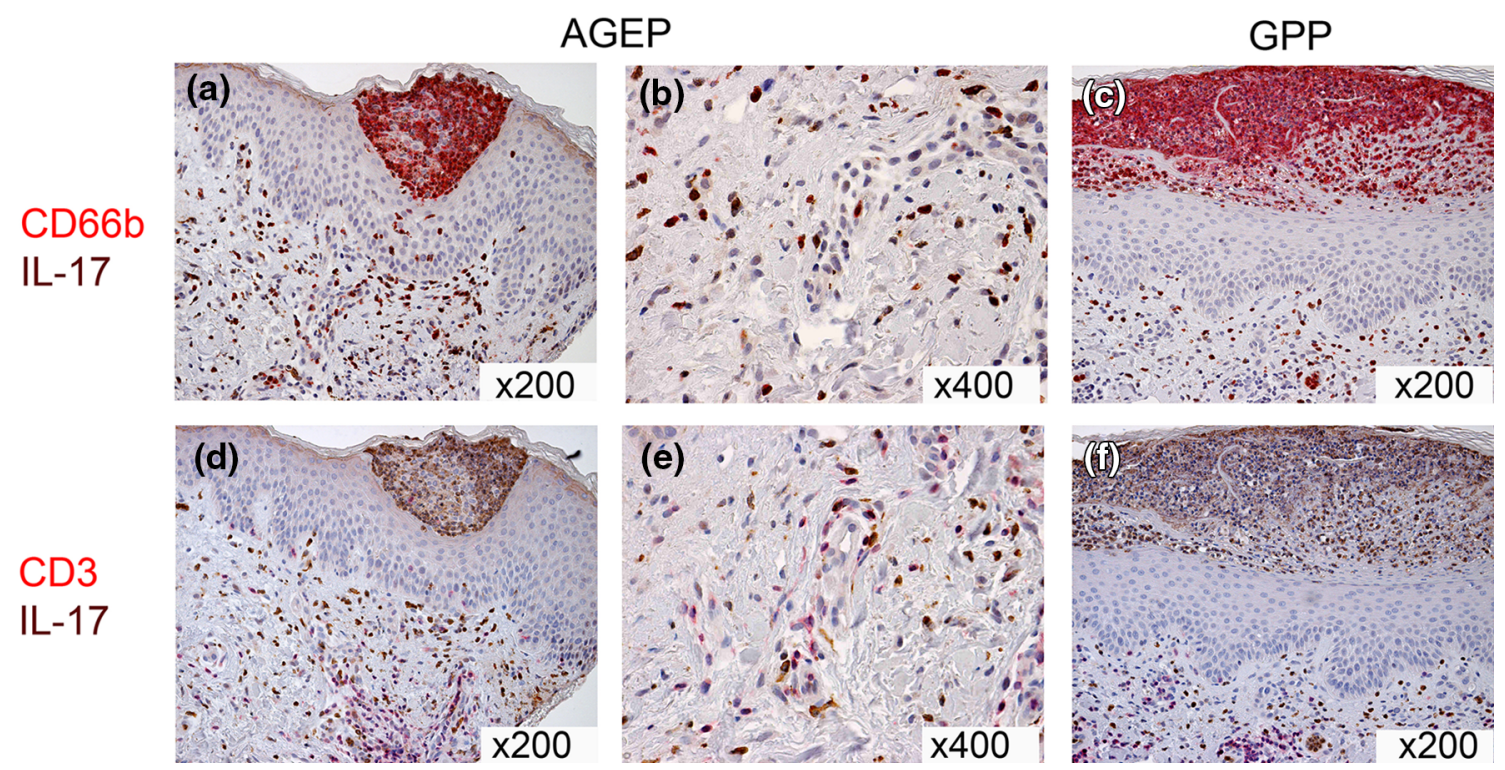

Fig. 2 Double immunohistochemical staining for IL-17 with CD3 (T cells), CD66b (neutrophils) (a-c). Immunohistochemical double staining of IL-17 (brown) and CD66b (red) in AGEP (a, b) and
GPP (c). d-f Immunohistochemical double staining of IL-17 (brown) and CD3 (red) in AGEP (d, e) and GPP (f). Original magnification $\times 200(\mathbf{a}, \mathbf{c}, \mathbf{d}, \mathbf{f})$ or $\times 400(\mathbf{b}, \mathbf{e})$ increased in subcorneal pustules, epidermis and dermis of AGEP and GPP as compared to normal skin. Furthermore, we show that innate immune cells such as neutrophils and mast cells are important cellular sources of IL-17A/F, while $\mathrm{T}$ cells account only for a minority of the total IL-17A/F-expressing cells. Our data are consistent with previous reports showing that mast cells and neutrophils rather than $\mathrm{T}$ cells are the predominant source of IL-17A/F in skin lesions of plaque psoriasis $[7-9,21]$.

In our study, IL-17 expression by neutrophils was assessed by in situ co-localization of both IL-17A/F mRNA and protein with CD66b. In humans, CD66b is expressed constitutively by neutrophils and eosinophils and CD66b expression levels increase upon granulocyte activation [24]. Since neutrophils have been shown to express IL17A/F after stimulation with IL-6 and IL-23, co-expression of IL-17 found in our study may indicate simultaneous upregulation of CD66b and IL-17 in neutrophils as a consequence of cytokine stimulation by IL- 6 and IL-23, both of which are cytokines intimately linked to the pathogenesis of psoriasis [3, 8]. To further confirm IL-17 expression by neutrophils, we excluded relevant expression of IL-17 by CD66 ${ }^{+}$eosinophils in AGEP (Suppl. Fig. 1). In GPP and normal skin, eosinophils are not part of the immune infiltrate.

In addition to neutrophils and mast cells, macrophages have also been shown to be an important cellular source of $\mathrm{IL}-17$ in murine and human inflammation, most prominently in lung inflammation $[4,20]$. Interestingly, we did observe co-localization of $\mathrm{IL}-17$ with $\mathrm{CD} 68^{+}$ cells in our immunofluorescence study, indicating that also in human skin inflammation, macrophages and dendritic cells can produce IL-17. However, our data does not rule out the possibility that an uptake of fragments from IL-17-producing cells could also explain the detection of IL-17A/F in macrophages. Further studies are needed to determine the contribution of macrophages to the production of IL-17 in cutaneous inflammation.

AGEP and GPP share clinical, genetic, histological, and immunological features [14]. In accordance with previous data, we show that high in situ expression of IL-17A/F is yet another similarity between the two diseases [6, 13]. IL$17 \mathrm{~A} / \mathrm{F}$ induces IL-36 expression in keratinocytes and IL-36 can induce further proinflammatory signals. Interestingly, loss of function in antagonism of IL-36 based on mutations in the IL-36 receptor antagonist IL-36Ra can cause GPP and IL-36Ra mutations can also be found in a subset of AGEP patients [2, 10, 14]. Therefore, in both GPP and AGEP, activation of keratinocytes by IL-17A/F may enhance local IL-36 expression, which-in the absence of functional antagonism-then drives neutrophil tissue inflammation.

Taken together, our findings position IL-17A/F expression as a common pathogenetic step in both AGEP and GPP, help to explain the similarity of their clinical presentation, and provide a rationale for a therapeutic approach with modern antibodies against IL-17A/F. 
(a)
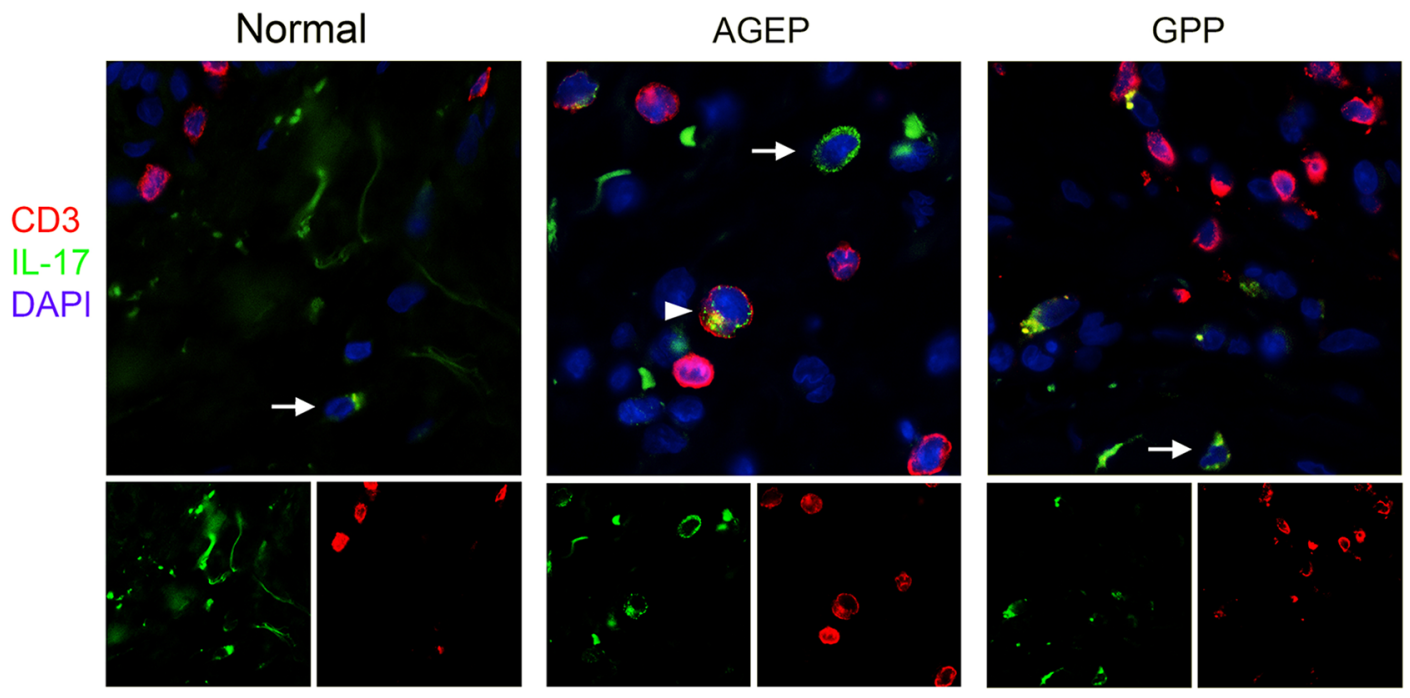

(b)
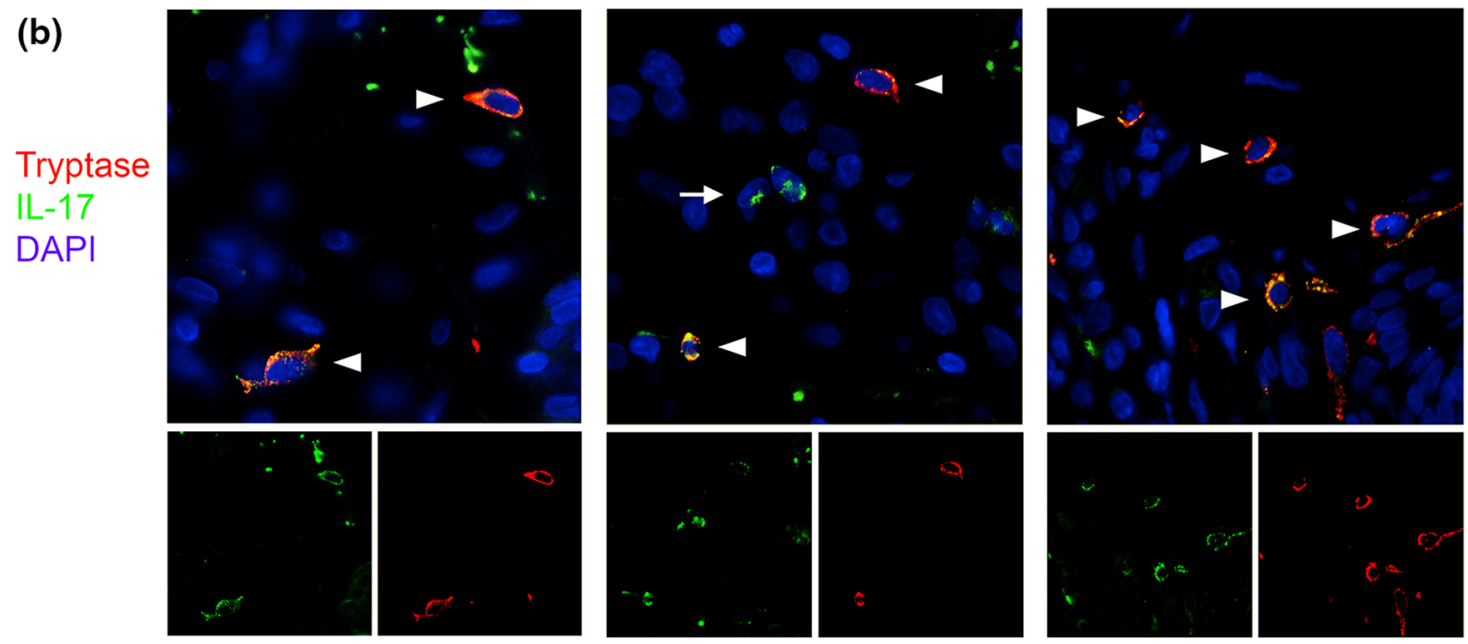

(c)
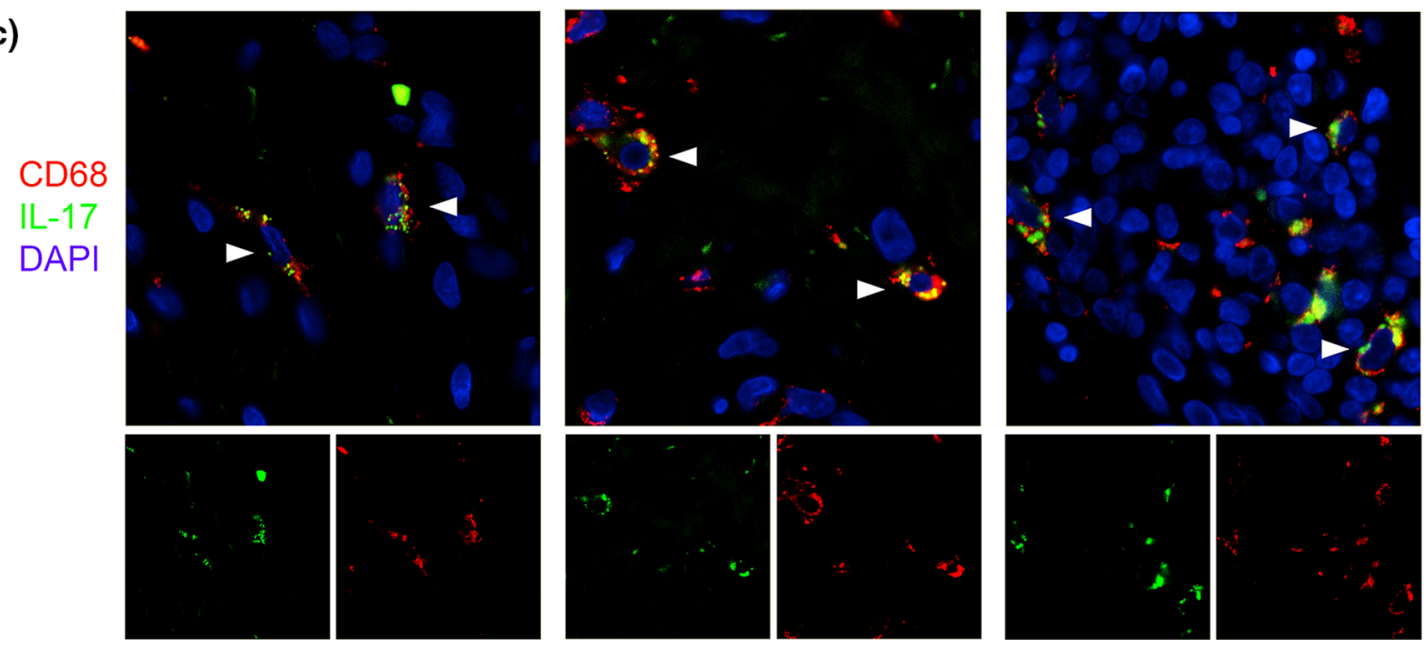

Fig. 3 Double immunofluorescence staining for IL-17 with CD3 (T cells), tryptase (mast cells), or CD68 (macrophages/dendritic cells). Double immunofluorescence staining of IL-17 in green with CD3 (a), mast cell tryptase (b), or CD68 (c) all in red in normal skin, AGEP, and GPP. Arrows indicate examples of IL-17-single positive cells, arrow heads indicate examples of IL-17-positive cells co-expressing the indicated markers. Nuclei were counterstained by DAPI (blue). (Original magnification $\times 800$ ) 
Acknowledgments We thank Dagmar Simon for providing us with the ECP antibody. This study was supported by a grant from the European Union FP7 (ADITEC 280873 and TIMER 281608 to M.U.), the Swiss National Science Foundation (3100A0-143718/1 to M.U.) and the Helmut Horten Foundation.

Conflict of interest None declared.

\section{References}

1. Britschgi M, Steiner UC, Schmid S, Depta JP, Senti G, Bircher A, Burkhart C, Yawalkar N, Pichler WJ (2001) T-cell involvement in drug-induced acute generalized exanthematous pustulosis. J Clin Invest 107(11):1433-1441. doi:10.1172/JCI12118

2. Carrier Y, Ma HL, Ramon HE, Napierata L, Small C, O'Toole M, Young DA, Fouser LA, Nickerson-Nutter C, Collins M, DunussiJoannopoulos K, Medley QG (2011) Inter-regulation of Th17 cytokines and the IL-36 cytokines in vitro and in vivo: implications in psoriasis pathogenesis. $\mathrm{J}$ Invest Dermatol 131(12):2428-2437. doi:10.1038/jid.2011.234

3. Dowlatshahi EA, van der Voort EA, Arends LR, Nijsten T (2013) Markers of systemic inflammation in psoriasis: a systematic review and meta-analysis. Br J Dermatol 169(2):266-282. doi:10. 1111/bjd.12355

4. Eustace A, Smyth LJ, Mitchell L, Williamson K, Plumb J, Singh D (2011) Identification of cells expressing IL-17A and IL-17F in the lungs of patients with COPD. Chest 139(5):1089-1100. doi:10.1378/chest.10-0779

5. Girolomoni G, Mrowietz U, Paul C (2012) Psoriasis: rationale for targeting interleukin-17. Br J Dermatol 167(4):717-724. doi:10. 1111/j.1365-2133.2012.11099.x

6. Kabashima R, Sugita K, Sawada Y, Hino R, Nakamura M, Tokura $Y$ (2011) Increased circulating Th17 frequencies and serum IL-22 levels in patients with acute generalized exanthematous pustulosis. J Eur Acad Dermatol Venereol 25(4):485-488. doi:10.1111/j.1468-3083.2010.03771.x

7. Keijsers RR, Hendriks AG, van Erp PE, van Cranenbroek B, van de Kerkhof PC, Koenen HJ, Joosten I (2014) In vivo induction of cutaneous inflammation results in the accumulation of extracellular trap-forming neutrophils expressing RORgammat and IL-17. J Invest Dermatol 134(5):1276-1284. doi:10.1038/jid.2013.526

8. Krueger JG (2012) Hiding under the skin: a welcome surprise in psoriasis. Nat Med 18(12):1750-1751. doi:10.1038/nm.3025

9. Lin AM, Rubin CJ, Khandpur R, Wang JY, Riblett M, Yalavarthi S, Villanueva EC, Shah P, Kaplan MJ, Bruce AT (2011) Mast cells and neutrophils release IL-17 through extracellular trap formation in psoriasis. J Immunol 187(1):490-500. doi:10.4049/ jimmunol.1100123

10. Marrakchi S, Guigue P, Renshaw BR, Puel A, Pei XY, Fraitag S, Zribi J, Bal E, Cluzeau C, Chrabieh M, Towne JE, Douangpanya J, Pons C, Mansour S, Serre V, Makni H, Mahfoudh N, Fakhfakh F, Bodemer C, Feingold J, Hadj-Rabia S, Favre M, Genin E, Sahbatou M, Munnich A, Casanova JL, Sims JE, Turki H, Bachelez H, Smahi A (2011) Interleukin-36-receptor antagonist deficiency and generalized pustular psoriasis. N Engl J Med 365(7):620-628. doi:10.1056/NEJMoa1013068

11. Mazzucchelli L, Blaser A, Kappeler A, Scharli P, Laissue JA, Baggiolini M, Uguccioni M (1999) BCA-1 is highly expressed in
Helicobacter pylori-induced mucosa-associated lymphoid tissue and gastric lymphoma. J Clin Invest 104(10):R49-R54. doi:10. 1172/JCI7830

12. Miossec P, Kolls JK (2012) Targeting IL-17 and TH17 cells in chronic inflammation. Nat Rev Drug Discov 11(10):763-776. doi: $10.1038 / \mathrm{nrd} 3794$

13. Nakamizo S, Kobayashi S, Usui T, Miyachi Y, Kabashima K (2010) Clopidogrel-induced acute generalized exanthematous pustulosis with elevated Th17 cytokine levels as determined by a drug lymphocyte stimulation test. $\mathrm{Br} \mathrm{J}$ Dermatol 162(6):1402-1403. doi:10.1111/j.1365-2133.2010.09705.x

14. Navarini AA, Valeyrie-Allanore L, Setta-Kaffetzi N, Barker JN, Capon F, Creamer D, Roujeau JC, Sekula P, Simpson MA, Trembath RC, Mockenhaupt M, Smith CH (2013) Rare variations in IL36RN in severe adverse drug reactions manifesting as acute generalized exanthematous pustulosis. J Invest Dermatol 133(7):1904-1907. doi:10.1038/jid.2013.44

15. Peters A, Lee Y, Kuchroo VK (2011) The many faces of Th17 cells. Curr Opin Immunol 23(6):702-706. doi:10.1016/j.coi.2011. 08.007

16. Schaerli P, Britschgi M, Keller M, Steiner UC, Steinmann LS, Moser B, Pichler WJ (2004) Characterization of human T cells that regulate neutrophilic skin inflammation. $\mathrm{J}$ Immunol 173(3):2151-2158

17. Schlapbach C, Yawalkar N, Hunger RE (2009) Human beta-defensin-2 and psoriasin are overexpressed in lesions of acne inversa. J Am Acad Dermatol 61(1):58-65. doi:10.1016/j.jaad. 2008.12.033

18. Sidoroff A, Halevy S, Bavinck JN, Vaillant L, Roujeau JC (2001) Acute generalized exanthematous pustulosis (AGEP)-a clinical reaction pattern. J Cutan Pathol 28(3):113-119

19. Simon D, Hoesli S, Roth N, Staedler S, Yousefi S, Simon HU (2011) Eosinophil extracellular DNA traps in skin diseases. J Allergy Clin Immunol 127(1):194-199. doi:10.1016/j.jaci.2010. 11.002

20. Song C, Luo L, Lei Z, Li B, Liang Z, Liu G, Li D, Zhang G, Huang B, Feng ZH (2008) IL-17-producing alveolar macrophages mediate allergic lung inflammation related to asthma. J Immunol 181(9):6117-6124

21. Taylor PR, Roy S, Leal SM Jr, Sun Y, Howell SJ, Cobb BA, Li $X$, Pearlman E (2014) Activation of neutrophils by autocrine IL17A-IL-17RC interactions during fungal infection is regulated by IL-6, IL-23, RORgammat and dectin-2. Nat Immunol 15(2):143-151. doi:10.1038/ni.2797

22. Venetz D, Ponzoni M, Schiraldi M, Ferreri AJ, Bertoni F, Doglioni C, Uguccioni M (2010) Perivascular expression of CXCL9 and CXCL12 in primary central nervous system lymphoma: $\mathrm{T}$-cell infiltration and positioning of malignant B cells. Int $\mathrm{J}$ Cancer 127(10):2300-2312. doi:10.1002/ijc.25236

23. Vermi W, Lonardi S, Bosisio D, Uguccioni M, Danelon G, Pileri S, Fletcher C, Sozzani S, Zorzi F, Arrigoni G, Doglioni C, Ponzoni M, Facchetti F (2008) Identification of CXCL13 as a new marker for follicular dendritic cell sarcoma. J Pathol 216(3):356-364. doi:10.1002/path.2420

24. Zhao L, Xu S, Fjaertoft G, Pauksen K, Hakansson L, Venge P (2004) An enzyme-linked immunosorbent assay for human carcinoembryonic antigen-related cell adhesion molecule 8 , a biological marker of granulocyte activities in vivo. J Immunol Methods 293(1-2):207-214. doi:10.1016/j.jim.2004.08.009 